\title{
Penjing: The Chinese Art of Bonsai
}

\author{
Wu-Zhong Zhou'and Xiao-Bai $\mathrm{Xu}^{2}$
}

Additional index words. history of bonsai, bonsai schools, bonsai patterns, bonsai plants, penjing, potted landscape

Summary. More and more people have become very interested in bonsai, a unique art of gardening that originated in China. However, most people know about Japanese bonsai and have only scant knowledge of Chinese bonsai. This paper gives a brief introduction to the history, local schools, and patterns of the bonsai art in the Chinese tradition, as well as a list of plants used for bonsai in China.

$\mathrm{S}$ ome misconceptions in horticultural history are very interesting, such as Prunus mume Sieb et Zucc., one of the famous 10 traditional flowers in China. Although it originated in China, it was given the common name "Japanese Apricot" by Westerners because they obtained the plant from Japan, and thought it native there. Similarly, most Westerners mistakenly credited bonsai to Japan.

\section{The history of bonsai}

Bonsai originated in China. It dates back to ancient times in the history of China. As early as the Yin and Zhou Dynasties, more than 3000 years ago, the Chinese began to cultivate ornamental plants and to pattern gardens after natural scenery. According to archaeological findings, potted flowers found in a mural in an Eastern Han Dynasty (A.D. 25-220) tomb in Wangdu County, Hebei Province, have been recognized as the embryonic form of bonsai by most experts in China.

${ }^{3}$ Associate Professor of Horticulture and Dean of Studies of China Training Center of Potted Landscape Arts; Vice-President and Chief Engineer of Qiong-Hua Institute of Landscape Horticulture, Jiangsu Agricultural College, 12 Su Nong Road, Yangzhou, 225001, Peoples Republic China. Currently visiting scholar in the $\mathrm{Hu}$ man Resources Dept. (TAES-HORT), Texas A\&M Univ., College Station.

${ }^{2}$ Professor of Horticulture, President of Chinese National Association for Potted Landscape Artists, and President of Qiong-Hua Institute of Landscape Horticulture.
The formative stage of bonsai took place during the Wei and Jin Dynasties (A.D. 220-420), when the strong influence of Confucianism, Taoism, and Buddhism resulted in the social mode of upholding simplicity and elegance, and expressing sentiment in landscape. Confucius said, "The wise find pleasure in water, the virtuous find pleasure in hills" (Analects). Thus, like landscape painting and poems in China, summarized as Shan Shui, or "mountains" and "water," Chinese bonsai is made of not only plants, but also of rocks and water, because it attempts to approach and display in symbolic form the essence ofnature. This is not a realistic or naturalistic presentation, but one that seeks to find the "nature of nature." It is for this reason that bonsai was given a precise name "penjing" (potted landscape) by Chinese experts.

Bonsai matured in the early Tang Dynasty (A.D. 618-907). A mural vividly depicting a maid of honor holding a potted landscape in her hands has been found in the tomb of Crown Prince Zhang Huai of the early Tang Dynasty, which was built in 706 in Qianxian County, Shanxi Province. We can learn a great deal from the poems of the Tang Dynasty; the artistic forms of potted landscape were stressed and various styles had already emerged.

The Northern Song Dynasty (A.D. 960-1279) saw unprecedented development in the art of painting, which, in turn, fostered the penjing art. Enjoying fantastic trees and grotesque stones became a common fad at that time. The famous Song paintings of "Eighteen Scholars," together with many poems and writings, indicate that the penjing art was well on its way toward perfection, and that two major kinds of penjing had evolved: mountain-and-water penjing and tree penjing. The latter was quite similar to that of modern penjing.

Chinese penjing flourished in the Ming and Qing Dynasties (A.D. 13681911). A study of relevant documents and extant penjing works shows that 
Acer buergeranum Miq.

Acer japonicum Thunb. var. aconitifolium Meehan

Acer mono Maxim.

Acer palmatum Thunb.

Adina rubella Hance

Akebia quinata (Houtt.) Decne.

Ampelopsis aconitifolia Bunge.

Ardisia crenata Sims

Ardisia japonica (Hornst.) blume.

Bambusa multiplex (Lour.) Rauschel.

Bambusa multiplex (Lour.) Rauschel 'Nana'

Bambusa ventricosa McClure

Berberis poiretii C.K. Schneid.

Berberis thunbergii DC

Berberis thunbergii DC 'Atropurpurea'

Buxus harlandii Hance

Buxus microphylla Siebold \& Zucc. var.

sinica Rehd \& E.H. Wils.

Camellia japonica L.

Camellia sasanqua Thunb.

Campsis grandiflora (Thunb.) K. Schum.

Caragana sinica (Buc'hoz) Rehd.

Carmona micropbylla (Lam.) G. Don.

Celastrus orbiculatus Thunb.

Celtis sinensis Pers.

Cephalotaxussinensis(Rehd. \& E. H.Wils.)

H.L. Li

Cercis chinensis Bunge

Chaenomeles cathayensis (Hemsl.) C.K. Schneid.

Chaenomeles speciosa (Sweet) Nakai

Chamaecyparis obutusa (Siebold \& Zucc.)

Endl. 'Breviramea'

Chamaecyparis obutusa (Siebold \& Zucc.)

Endl. 'Filicoides'

Chamaecyparis pisifera (Siebold \& Zucc.)

Endl. 'Filifera'

Chamaecyparis pisifera (Siebold \& Zucc.)

Endl. 'Squarrosa'

Chimonanthus praecox (L.) Link

Citrus aurantium L. var. amara Engl.

Citrus medica L. var. sarcodactylis (Noot.)

Swingle

Citrus reticulata Blanco

Cotinus coggygria Scop.

Cotoneaster horizontalis Decne

Cotoneaster microphyllus Wallich ex Lindl.

Crataegus pinnatifida Bunge

Cryptomeria japonica (L.f.) D. Don.

'Vilmoriniana'

Cupressus funebris Endl.

Cycas revoluta Thunb.

Cycas rumphii Miq.

Cydonia sinensis Thouin

Damnacanthus indicus C.F. Gaertn.

Daphne genkwa Siebold \& Zucc.

Daphne odora Thunb.
Diospyros armata Hemsl.

Diospyros kaki L.f.

Diospyros rhombifolia Hemsl.

Ebretia microphylla Lam.

Elaeagnus pungens Thunb.

Enkianthus quinqueflora Lour.

Euonymus alatus (Thunb.) Siebold

Euonymus bungeanus Maxim.

Euonymus fortunei (Turcz) Hand.-Mazz.

Fatsia japonica (Thunb.) Decne.

Ficusmicrocarpa Hugel ex Kunth \& Bouche

Ficus pumila L.

Fortunella crassifolia Swingle

Fortunella margarita (Lour.) Swingle

Fraxinus chinensis Roxb.

Gardenia jasminoides Ellis

Ginkgo biloba L.

Glyptostrobus pensilis (D. Don) C. Koch

Hedera helix L. 'Marginata'

Hedera nepalensis C. Koch

Ilex chinensis Sims.

Ilex cornuta Lindl.

Ilex crenata Thunb.

Jasminum floridum Bunge.

Jasminum mesnyi Hance

Jasminum nudiflorum Lindl.

Juniperus communis $\mathrm{L}$.

Juniperus formosana Hayata.

Juniperus rigida Siebold \& Zucc.

Kalopanax septemlobus (Thunb.) Koidz.

Lagerstroemia indica L.

Ligustrum sinense Lour.

Liquidambar formosana Hance.

Lonicera japonica Thunb.

Loropetalum chinense (R.Br.) D. Oliver

Loropetalum chinense ( $\mathrm{R}$. Br.) D. Oliver.

var. rubrum Yich

Lycium chinense Mill.

Magnolia liliflora Desr.

Mahonia fortunei (Lindl.) Fedde.

Malus asiatica Nakai

Malus halliana Koehne

Malus prunifolia (Willd.) Borkh.

Malus pumila Mill.

Malus spectabilis (Ait.) Borkh.

Metasequoia glyptostroboides H.H. Hu \&

Cheng

Millettia reticulata Benth

Nandina domestica Thunb.

Osmanthus fragrans (Thunb.) Lour.

Osmanthusheterophyllus(G. Don) P.S. Green

Parthenocissus tricuspidata (Siebold \&

Zucc.) Planch

Phyllostachys bambusoides Siebold \& Zucc.

'Tanakae'

Phyllostachysnigra(Lodd. ex Lindl.) Munro

Picea asperata M.T. Mast.

Pierisjaponica (Thunb.) D. Don ex G. Don
Pinus armandii Franch

Pinus bungeana Zucc. ex. Endl.

Pinus parviflora Siebold \& Zucc.

Pinus taiwanensis Hayata

Pinus thunbergii Parl.

Pistacia chinensis Bunge

Pleioblastusargenteo-striatus(Regel) Nakai

Podocarpusmacropbyllus(Thunb.) D. Don

Podocarpusmacrophyllus(Thunb.) D. Don var. maki Endl.

Podocarpus nagi (Thunb.) Zoll \& Moritzi ex Mak.

Prunus cerasifera J.F. Ehrh.

Prunus japonica Thunb.

Prunus mume Siebold \& Zucc.

Prunus persica (L.) Batsch. 'Densa'

Psendolarix amabilis (J. Nels.) Rehd.

Punica granatum L.

Pyracantha fortuneana (Maxim.) H.L. Li

Rhamnus parvifolia Bunge

Rhapis humilis Blume.

Rhapis mutifida Henry

Rhododendron L. spp.

Rhus sylvestris Siebold \& Zucc.

Rosa chinensis Jacq.

Sabina chinensis (L.) Antoine

Sabina chinensis (L.) Antoine 'Aurea'

Sabina chinensis (L.) Antoine var. sargentii

Cheng et L.K. Fu

Sabina procumbens(Endl.) Iwata et Kusata Sabina squmata (Buch.-Ham.) Ant. 'Meyeri' Sageretia theezans (L.) Brongn

Sasa auricoma Mak. \& Shib.

Schefflera octophylla (Lour.) Harms.

Schisandra chinensis (Turcz.) Baill.

Sciadopitys verticillata Siebold \& Zucc.

Serissa foetida (L.F.) Lam.

Spiraea cantoniensis Lour.

Spiraea japonica L.f.

Syringa pubescens Turcz.

Syzygium buxifolium Hook. et Arn.

Tamarix chinensis Lour.

Taxodium ascendens Brongn.

Taxodium distichum (L.) L. Rich

Taxus chinensis (Pilg.) Rehd. var. mairei

Cheng et L.K. Fu

Taxus cuspidata Siebold \& Zucc.

Taxus cuspidata Siebold \& Zucc. 'Nana'

Ternstroemiagymnanthera (Wight \&Arn.)

T. Sprague

Trachelospermum jasminoides(Lindl.) Lem.

Ulmus parvifolia Jacq.

Vitex negundo L.

Vitis vinifera $\mathrm{L}$.

Wisteria sinensis (Sims) Sweet

Wisteria sinensis(Sims) Sweet var. alba Lindl.

Xylosma japonicum (Walp.) A. Gray

Zelkova schneideriana Hand.-Mazz. various artistic features were evident during that period, and that penjing works tended to embody pictorial conception and poetic flavor.
In the late years of the Qing Dynasty and thereafter, Chinese penjing declined for a time, but, in recent decades, it has rejuvenated and has been developing considerably. Many new ideas and technical innovations based on the old traditions have found vivid expressions in the penjing art of today. 


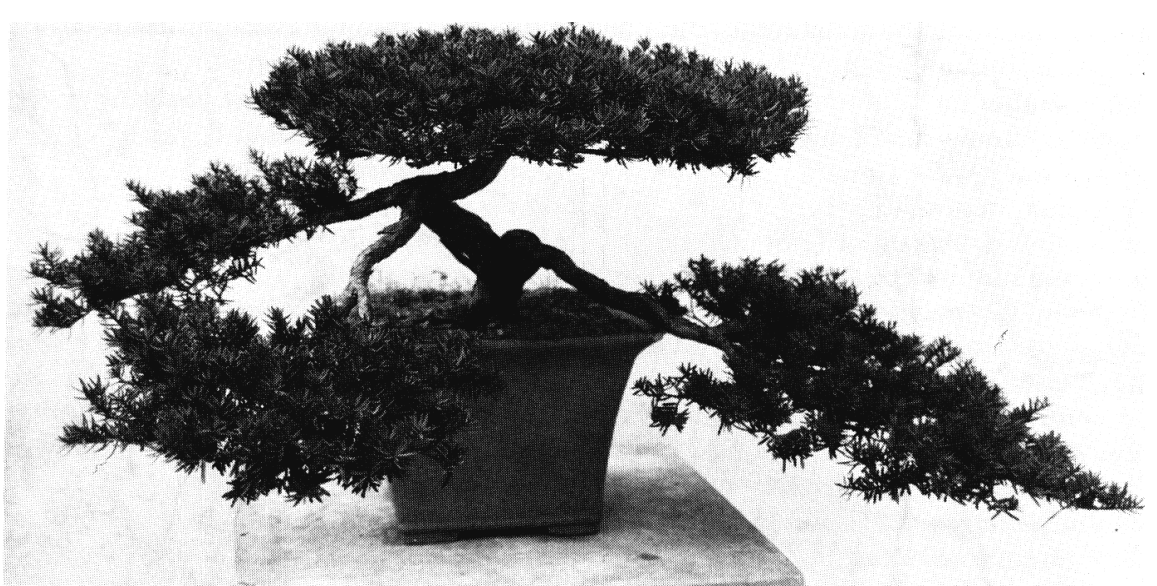

Fig. 1. Bonsai pruned in the shape of layers of clouds (Taxus cuspidata Sieb. et Zucc. cv. Nana).

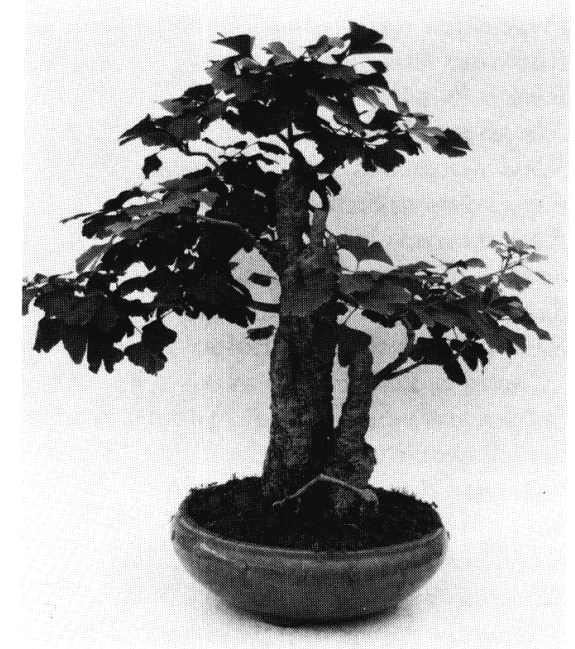

Fig. 2. Bonsai of maidenhair tree (Ginkgo biloba $L$.).

As mentioned previously, we can see that penjing, as a particular kind of gardening, is closely tied with landscape painting and poetry in China. Indeed, the three arts of poetry, landscape painting, and penjing are thought of as interdependent, each requiring an understanding of the others, with proficiency in each necessary to achieve proficiency in any one. Thus, penjing art is called "silent poetry, three-dimensional painting" in China. It has already become an integral part of the Chinese peoples' leisure cultures.

It was during the Tang Dynasty (A.D. 1127-1279) that Chinese bonsai art found its way to Japan, where it was then introduced into the continents of Europe, America, and Australia at the beginning of the 20th century. So far, it has become a worldwide art with different styles, such as Japanese, English, and American (e.g., "Pompon"), etc. Plants used in Chinese bonsai are listed in Table 1.

\section{The local schools of bonsai art in china}

The bonsai art is now spreading throughout the whole country, especially in eastern, central, and southern China, where the climate is mild and wet. China has vast territories, distinguished and varied local scenery, and material resources (plants and rocks) for bonsai, all of which, along with different aesthetic standards and techniques of bonsai-making, make it ready for forming various local schools of bonsai art. The main local schools of bonsai in China are as follows:

Yangzhou Penjing. Representative trees of this genre are pine (Pinus L.), cypress (Cupressus L.), Chinese elm (Ulmus parvifolia Jacq.), and Chinese littleleaf box (Buxus microphylla Siebold \& Zucc. var. sinca Rehd. \& E.H. Wils.), which are meticulously wired with palm fibers and carefully

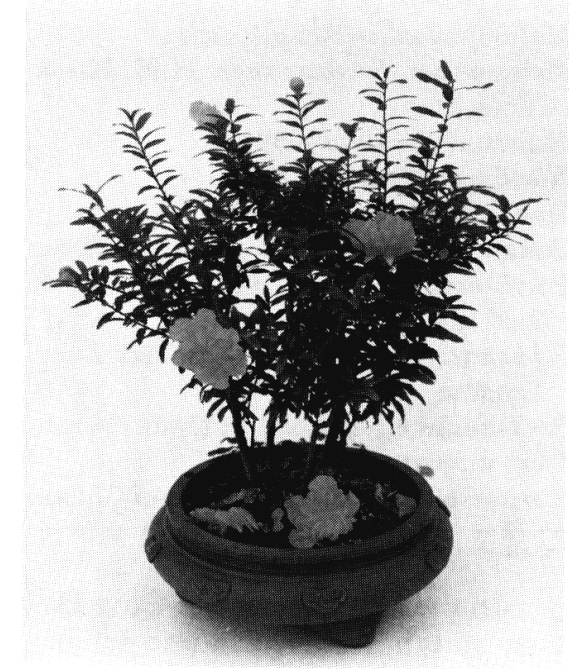

Fig. 3. Bonsai of pomegranate (Punica granatum $L$.).

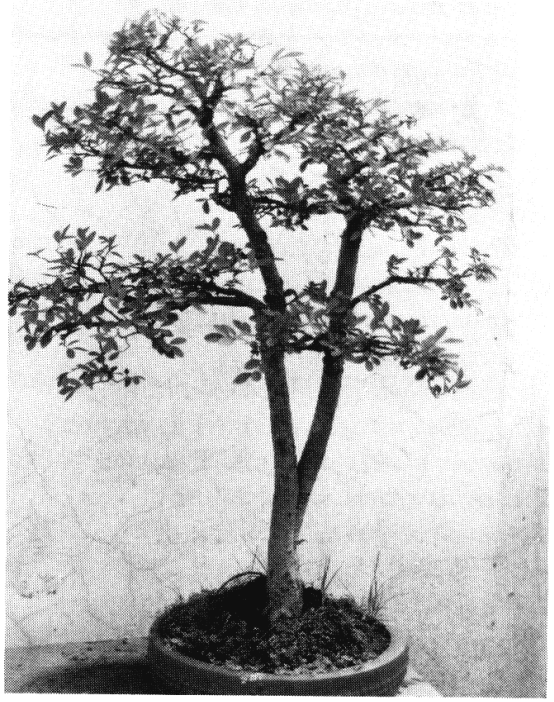

Fig.4. Straight trunk pattern (Ulmus parvifolia Jacq.).

pruned in the shape of layers of clouds (Fig. 1). Yangzhou tree penjing best expresses sobriety and elegance. Mountain-and-water penjing as well as water-and-land penjing has many forms that appear to give both poetic and picturesque effects.

Suzhou penjing. Known for its classic beauty, Suzhou tree penjing employs Chinese elm, hedge sageretia [Sageretia theezans (L.) Brongn.], trident maple (Acer buergeranum Miq.), and plum (Prunus L.) for themes. Training methods are mostly rough wiring with meticulous pruning to shape branches like clusters of clouds.

Sichuan penjing. Trees such as Buddhist pine [Podocarpus macrophyllus (Thunb.) D. Don], maidenhair tree (Ginkgo biloba L.) (Fig. 2), spiny persimmon (Diospyros armata Hemsl.), snow-in-summer [Serissa foetida (L.F.) Lam.], and flowering quince

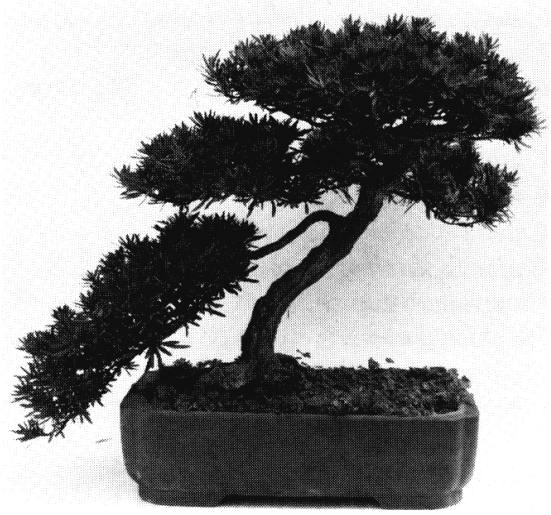

Fig. 5. Slanting trunk pattern /Podocarpus macrophyllus (Thunb.) D. Don var. maki Endl.]. 


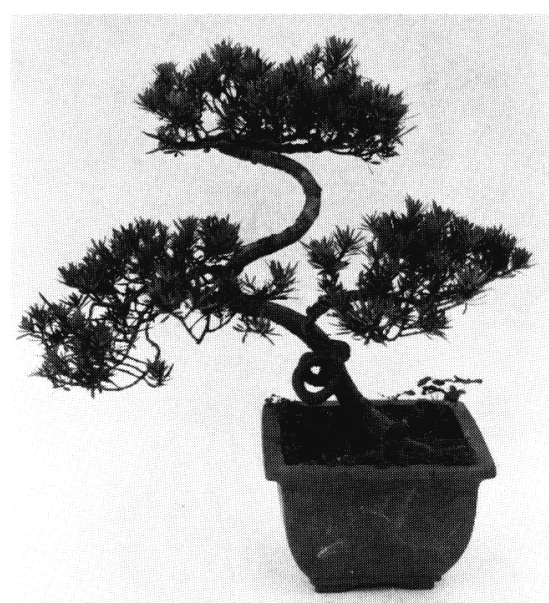

Fig. 6. Twisted trunk pattern [Podocarpus macrophyllus (Thunb.) D. Don var. maki Endl.].

[Chaenomeles lagenaria (Loisel.) G. Koidz.] often are seen in Sichuan tree penjing. Wiring with palm fibers and trimming shapes the branches and leaves into "plates" and makes the trunks expressively sinuous. Sichuan mountain-and-water penjing, as well as water-and-land penjing, is noted for serenity, grace, steepness, and majesty.

Lingnan penjing. Hedge sageretia, Chinese elm, orange jasmine (Murraya paniculata L. Jack), and Philippine tea (Ehretia microphylla Lam.) are typical penjing trees in this region. The chief method of training is to retain the branches, but cut the trunks so that the trees look old and hardy, natural, and graceful. The beautiful and fantastic mountain-and-water penjing is also very attractive.

Shanghai penjing. This metropolis boasts a large variety of trees (Fig. 3) for making penjing. They are tied with wires and pruned. Shanghai tree penjing is considered sprightly and vigorous. Miniature penjing is exquisite and mountain-and-water pen-

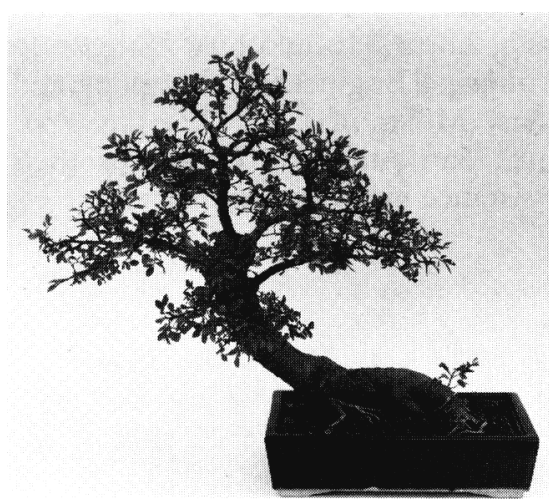

Fig. 7. Recumbent trunk pattern (Ulmus parvifolia Jacq.)

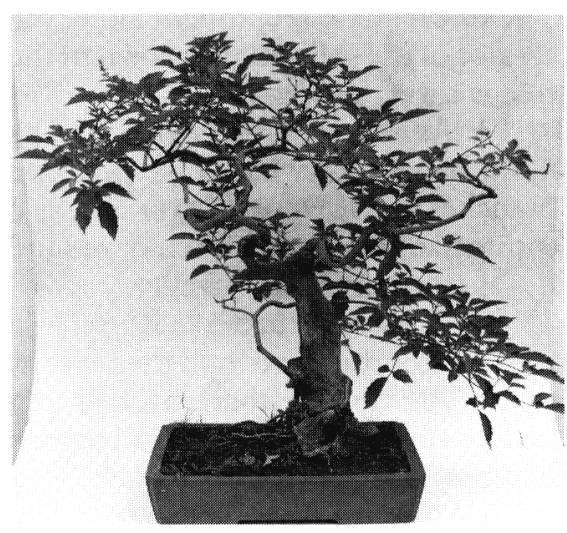

Fig. 8. Withered trunk pattern (Vitex negundo $L$.)

jing is a unique blend of grace and vigor.

Huizhou tree penjing. Plum, common juniper (Juniperus communis L.) and formosa pine (Pinus taiwanensis Hayata) are representative of Huizhou penjing trees. Rough wiring and rough pruning are typical Huizhou techniques for making tree penjing, which is known for its rusticity and grotesqueness.

Zhejang tree penjing. Pine and cypress usually are collected, tied with either palm fibers or metal wires, and pruned to make Zhejang tree penjing highly natural and picturesque in both form and spirit.

Nantong tree penjing. The tree mostly used for penjing is shrubby yew podocarpus [Podocarpus macrophyllus (Thunb.) D. Donvar. maki Endl.] Its trunk is wired with palm fibers into an " $\mathrm{S}$ " shape (two curves and a half) with branches pruned into clear-cut pieces.

Apart from those mentioned previously, schools of penjing in Fujian, Henan, Hubei, Nanjing, Hunan, Guizhou, and Xuzhou either have al-

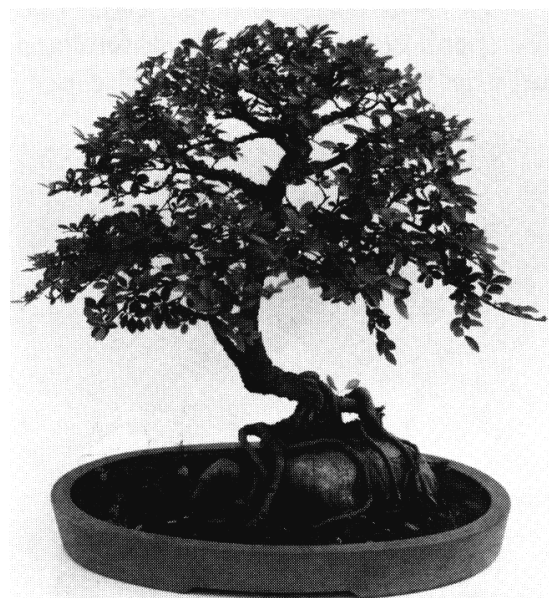

Fig. 9. Pattern of root attached to a rock (Ulmus parvifolia Jacq.).

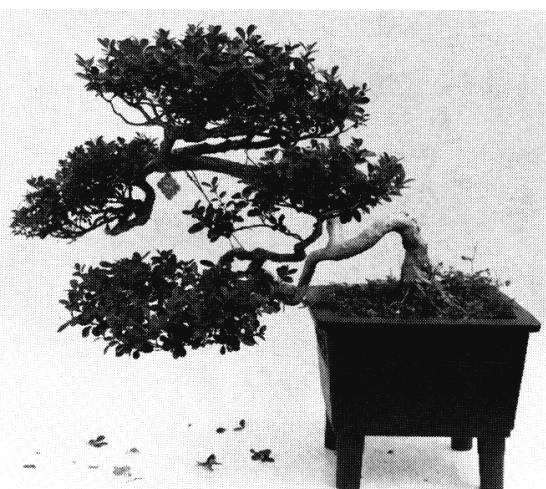

Fig. 10. Overlooking pattern [Buxus sinica (Rehd. et Wils.) Cheng ex M. Cheng].

ready developed or are still undergoing development with their own respective local characteristics.

\section{The patterns of Chinese bonsai}

Bonsai (tree potted landscape) in the Chinese tradition are divided into the following patterns according to their shapes:

A) Straight Trunk (Fig. 4). The tree trunk grows erect and the branches spread in gradations, resembling a huge, towering tree in its natural setting. This pattern, in turn, can be divided into three subpatterns: 1) single trunk, 2) double trunk, and 3) multitrunk (three or more).

B) Slanting Trunk (Fig. 5). The tree trunk inclines to one side. Several branches spread naturally on the top of the tree and look elegant.

C) Twisted Trunk (Fig. 6). The tree trunk is twisted to the left and right. The branches spread to both sides in clear gradations.

D) Recumbent Trunk (Fig. 7).

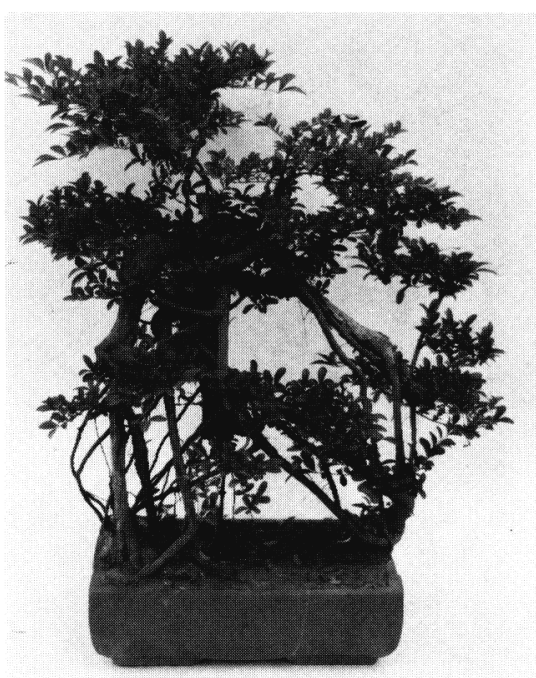

Fig. 11. Linked roots pattern (Ligustrum sinense Lour.). 


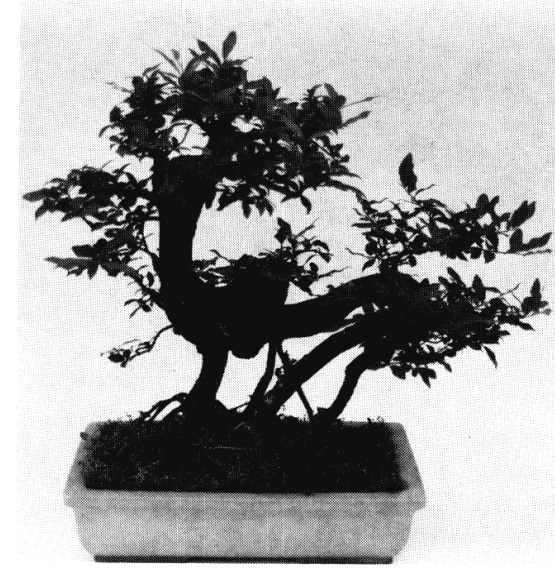

Fig. 12. Linked roots pattern (Diospyros armata Hemsl.).
The tree trunk is recumbent along the surface of the soil and the crown of the tree is thrust upward.

E) Withered Trunk (Fig. 8). The main trunk is withered, but the branches and leaves are luxuriant, as if spring had come to a withered tree and it was brimming with vitality.

F) Root Attached to a Rock (Fig. 9). The tree roots grow on the rocks in a pot. The tree is either attached to a rock or stands in a rock crevice, resembling an age-old tree on a peak.

G) Overlooking (Fig. 10). The crown of the tree inclines to one side, just like that of a tree on the bank of a pond overlooking the water.

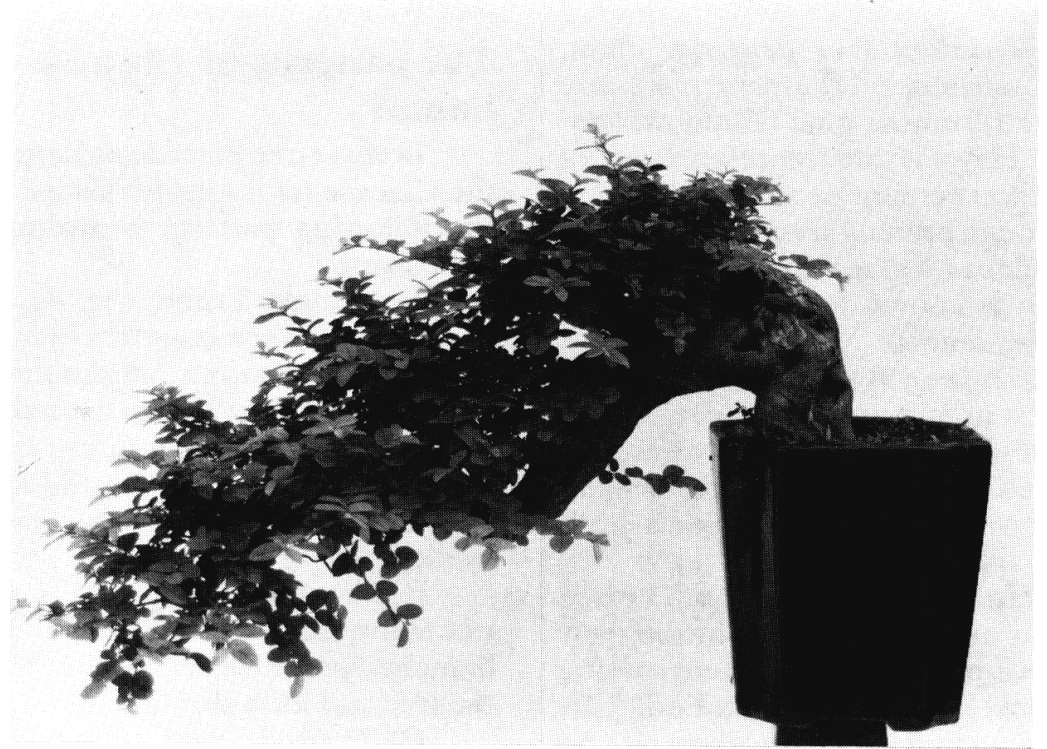

Fig. 13. Overhanging pattern [Sageretia theezans (L.) Brongn].

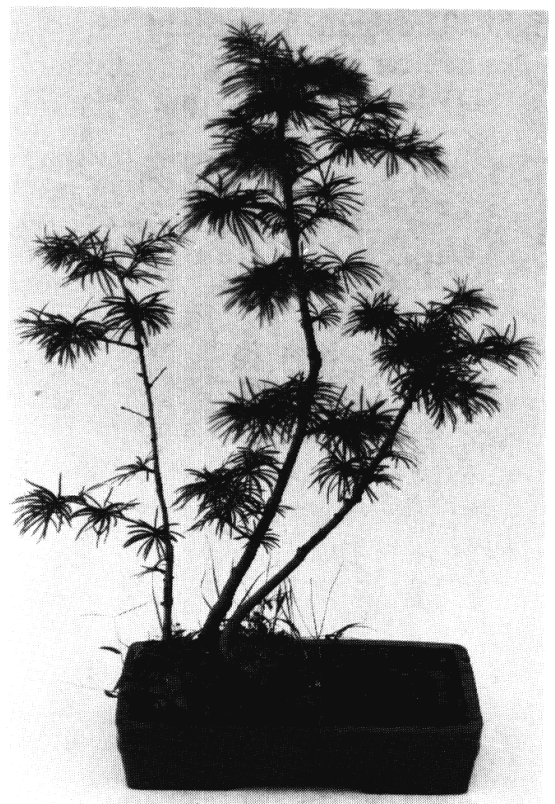

Fig. 14. Diverse forest pattern [Pseudolarix amabilis (Nels.) Rehd.].
H) Linked Roots (Figs. 11 and 12). The exposed roots of two or more trees are linked together. The trunks, at varying heights and in a charming, irregular array, have a special style.

I) Overhanging (Fig. 13). The tree trunk coils and bends downward and the branches overhang the pot,

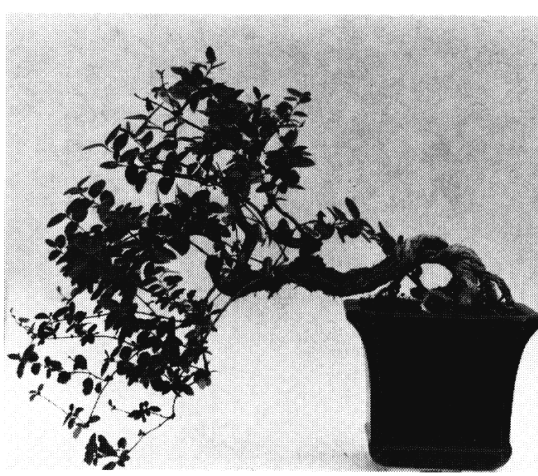

Fig. 15. Vine pattern (Lonicera japonica Thunb.).

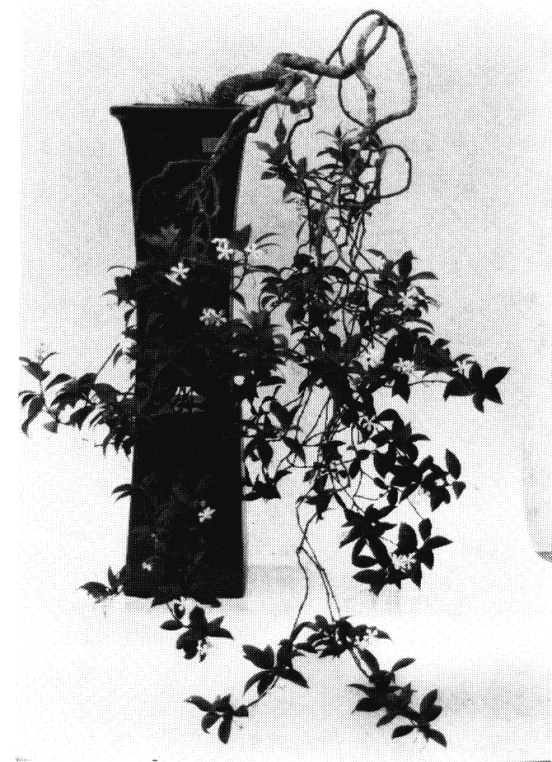

Fig. 16. Vine pattern [Trachelospermum jasminoides (Lindl.) Lem.].

just like age-old trees in rock crevices on precipices and sheer cliffs, defying danger and standing firm and tenacious. If the tree's top does not extend beyond the bottom of the pot, it is called a partially overhanging cliff pattern. If the tree's top overhangs to a very large degree and extends beyond the bottom of the pot, it is called a fully overhanging cliff pattern.

J) Diverse Forest (Fig. 14). Three or more trees are planted in a pot. Interspersed with overlapping shadows, they grow into lush woods and have the natural charms of the wilderness.

K) Vine (Figs. 15 and 16): The plants used for this type of bonsai are vines, such as wisterias, Japanese honeysuckle, star jasmine, etc.

\section{Acknowledgement}

We thank Zhao Qingquan, vice president of the Chinese National Association for Potted Landscape Artists; Zhou Hongkui of Yangzhou Municipal Engineering Company; and Mary Miller of Lone Star Growers, Inc., San Antonio, Texas, for their assistance in preparing this paper. 